\title{
Penanganan Cedera Kepala Berat disertai Intoksikasi Alkohol Akut dengan Panduan Transcranial Doppler Pascaoperasi
}

\author{
Ida Bagus Krisna J. Sutawan*), Syafruddin Gaus**), Bambang J. Oetoro ${ }^{* * *}$ ) \\ ${ }^{*}$ Departemen Anestesiologi dan Terapi Intensif Fakultas Kedokteran Universitas Udayana RSUP Sanglah, ${ }^{* *}$ \\ Departemen Anestesiologi \& Terapi Intensif Fakultas Kedokteran-Universitas Hasanudin-RSP Dr. Wahidin \\ Makassar, ${ }^{* * *}$ Departemen Anestesiologi dan Terapi Intensif Rumah Sakit Mayapada Jakarta
}

\begin{abstract}
Abstrak
Cedera kepala yang disertai dengan intoksikasi alkohol akut memerlukan suatu perhatian khusus selain karena nilai GCS yang digunakan untuk menggolongkan derajat beratny cedera kepala penilaiannya dipengaruhi oleh intoksikasi alkohol, juga karena pengaruh alkohol pada susunan saraf pusat. Transcranial doppler (TCD) dapat digunakan secara noninvasif untuk mengevaluasi aliran darah ke otak, tekanan intrakranial dan tekanan perfusi serebri. Panduan TCD membantu dalam pengambilan keputusan pada perawatan pascaoperasi. Seorang laki-laki 23 tahun dengan GCS E1V2M4, dari foto CT-scan didapatkan subdural hematoma lobustemporoparietal kanan yang menyempitkan sisterna ventrikel lateralis kanan dan deviasi midline sejauh 0,54 cm ke kiri. Pasien ditangani sesuai dengan standar prosedure operasional cedera kepala berat, operasi evakuasi hematoma dan kranietomi berjalan dengan lancar. Dua belas jam pascaoperasi pada pemeriksaan TCD didapatkan aliran darah dan tekanan intrakranial normal, sehingga pasien diextubasi dengan GCS 15 hanya dalam waktu 18 jam pascaoperasi.
\end{abstract}

Kata kunci: Cedera kepala, intoksikasi alkohol akut, transcranial Doppler

JNI 2018;7 (1): 103-9

\section{Management of Severe Head Injuri with Alcohol Intoxication guided by Pascaoperatif Transcranial Doppler}

\begin{abstract}
Head injury associated with alcholol intoxication needs special concideration, not only because GCS which is used to classifying the severity of head injury is affected by alcohol intoxication, but also because of the effect of alcohol to the central nervous system. Transcranial doppler (TCD) can be used noninvasifly to evaluate cerebral blood flow, intracranial pressure and cerebral perfusion pressure. TCD guidance helps in decision making on postoperative management. Twenty three years old male, GCS E1V2M4, on a CT-scan image there is a subdural right lobustemporoparietal hematoma constricting the right ventricular lateral system and a midline deviation of $0.54 \mathrm{~cm}$ to the left. Patient was managed according to standart operational procedure for severe head injury, hematoma evacuation and craniectomy procedures went smoothly. Twelve hours postoperative, from TCD examination obtained normal blood flow and intracranial pressure, so patients were extubated with GCS 15 in just 18 hours postoperatively.
\end{abstract}

Key word: Head injury, acute alcohol intoxication, Transcranial Doppler

JNI 2018;7 (1): 103-9 


\section{Pendahuluan}

Intoksikasi alkohol meningkatkan angka kejadian cedera kepala akibat kecelakaan di jalan raya, lebih dari 40 persen pasien yang mengalami kecelakaan sepeda motor yang fatal di USA mengalami intoksikasi alkohol pada saat kejadian. Selain itu adanya intoksikasi alkohol juga meningkatkan angka morbiditas dan mortalitas dari cedera kepala yang dialami oleh pasien. ${ }^{1}$ Intoksikasi alkohol menyebabkan depresi susunan saraf pusat (SSP) yang ditandai dengan penurunan kesadaran yang jika dinilai dengan GCS maka akan ada penurunan dari GCS yang sebanding dengan beratnya intoksikasi alkohol tersebut. Oleh karena itu, pasien trauma kepala yang disertai dengan intoksikasi alkohol biasanya dinilai dengan skor GCS yang lebih rendah dibandingkan dengan pasien tanpa intoksikasi alkohol. $^{2}$

Transcranial doppler (TCD) adalah salah satu alat non invasif yang dapat digunakan untuk membantu memonitoring pasien-pasien yang mengalami cedera kepala, terutama pada pasien yang tidak dipasang monitoring tekanan intrakranial. Informasi mengenai keadaan pasien yang dapat diketahui dari pemeriksaan TCD diantaranya adalah evaluasi aliran darah ke otak yang dapat dilihat dari mean velocity $(\mathrm{mFV})$, tekanan intrakranial yang dapat dilihat dari nilai pulsatif index (PI), non invasif cerebral perfusion pressure (nCPP) yang didapatkan dari rumus yang melibatkan tekanan darahrerata, $\mathrm{mFV}$ dandiastolik FV. Selanjutnya pada neurointensive care unit, juga dengan TCD juga dapat dibedakan apakah peningkatan tekanan intrakranial disebabkan oleh aliran darah otak yang kurang atau aliran darah otak yang berlebihan (hyperemia). Selain itu jika diperlukan maka dengan TCD juga dapat dilakukan beberapa test untuk melihat keutuhan dari autoregulasi. ${ }^{3}$ Namun demikian penemuanpenemuan yang didapatkan melalui TCD tetap harus diselaraskan pemeriksaan-pemeriksaan lainnya utnuk mendapatkan penatalaksanaan yang terbaik bagi pasien. ${ }^{4}$

Pada laporan kasus ini akan dibahas mengenai seorang pasien yang mengalami cedera kepala dengan intoksikasi alkohol. Pasien masuk rumah sakit dengan GCS 6 dan dinilai sebagai cedera kepala berat, sehingga langsung dilakukan resusitasi serta intubasi untuk menjaga jalan nafas di UGD. Selanjutnya dilakukan tindakan craniotomi evakuasi clot dan dekompresi karena pada CT scan ditemukan adanya subdural hematoma (SDH) dengan tanda-tanda peningkatan tekanan intrakranial. Pascaoperasi pasien dirawat di ICU, yang selanjutnya di extubasi 18 jam kemudian dengan GCS 15, setelah pada pemeriksaan TCD didapatkan aliran darah dan tekanan intrakranialnya normal. Selanjutnya pasien pindah ke ruangan pada hari yang ke-2.

\section{Kasus}

Seorang laki-laki umur 23 tahun, datang diantar polisi setelah mengalami kecelakaan lalu lintas kurang lebih 1 jam sebelum masuk rumah sakit. Pasien pengendara sepeda motor, menggunakan helm dan jatuh sendiri menabrak tembok dan kepala terbentur tembok, pasien langsung tidak sadar dengan riwayat muntah tiga kali dan keluar darah dari telinga kiri, sedangkan riwayat kejang tidak ada. Pada saat tiba di UGD pasien berbau alkohol yang sangat menyengat dari mulutnya dengan GCS E1V2 M4. Selanjutnya secara stimultan dilakukan primary survey, dipasang monitor dan diambil sampel darah. Pada monitor didapatkan tekanan darah 100/80 $\mathrm{mmHg}$, nadi 72 $\mathrm{x} / \mathrm{mnt}$ dan saturasi $\mathrm{O}_{2} 98 \%$

A (airway): pasien mengalami sumbatan jalan nafas partial dengan adanya suara mengorok, kemudian dilakukan in line intubasi dengan obat-obatan fentanyl $100 \mu \mathrm{g}$, rocuronium $50 \mathrm{mg}$ dan menggunakan target control infused (TCI) propofol model Schnider dengan target effect $1 \mu \mathrm{g} / \mathrm{ml}$, selanjutnya dikontinyu $0,5 \mu \mathrm{g} / \mathrm{ml}$. Selanjutnya dipasang collar brace.

B (breathing): Pernafasan adekuat vesicular, ronchi dan wheezing negatif pada kedua lapangan paru, laju nafas $10 \mathrm{kali} / \mathrm{menit}$ dengan bagging.

C (circulation): tekanan darah 97-112/73-82, Nadi $72-85$ kali/mnt dengan saturasi $96-98 \%$, dilakukan pemasangan infus $\mathrm{NaCl} 0,9 \% 65 \mathrm{cc} /$ jam.

D (Disability): merespon dengan nyeri 

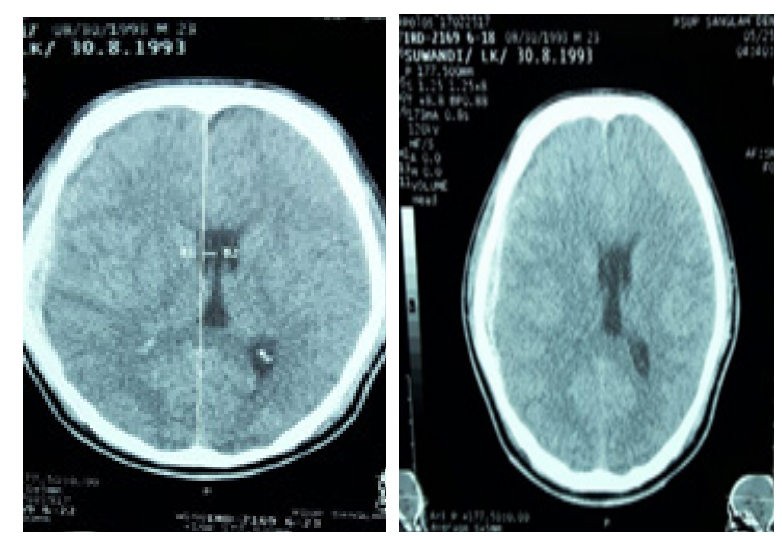

Gambar 1. MSCT menunjukan adanya SDH dan Midline Shift

E (Exposure dan Environment): pasien dilakukan pemeriksan pada seluruh tubuh, ada beberepa jejas di tungkai atas dan bawah, tetapi tidak ada yang bermakna, kemudian pasien diselimuti kembali, suhu 37 derajat celcius.

Pada secondary survey didapatkan, berat badan: $\pm 70 \mathrm{~kg}$; Tinggi badan $170 \mathrm{~cm}$; IMT $23.87 \mathrm{~kg} /$ $\mathrm{m} 2$; temperature axilla $37,3^{\circ} \mathrm{C}$.

Sistem saraf pusat: GCS E1VxM1 on sedasi, pupil bulat isokor $2 \mathrm{~mm} / 2 \mathrm{~mm}$, reflex cahaya $+/+$ Respirasi: on portable ventilator mode $\mathrm{CMV}, \mathrm{TV}$ $500 \mathrm{ml}$, RR $10 \mathrm{X} /$ menit, tidak ada rhonki dan wheezing, saturasi oksigen perifer $99 \%$

Kardiovaskuler: tekanan darah 110/70 mmHg; nadi 72 kali permenit, Bunyi jantung 1 dan 2 tunggal, reguler, tidak ada murmur

Abdomen: Tidak ada distensi, bising usus normal. Urogenital: terpasang kateter urine dengan residual urine $200 \mathrm{cc}$, warna kuning jernih.

Muskuloskeletal: gigi geligi utuh, akral hangat, tidak ada fraktur pada tungkai atas maupun bawah.

\section{Pemeriksaan Penunjang}

Darah lengkap: dalam batas normal (dbn), Kimia Klinik: SGOT/SGPT, BUN/SC: dbn, Na \& K: dbn, BSA $194 \mathrm{mg} / \mathrm{dL}, \mathrm{AGD}: \mathrm{pH}$ 7.27; $\mathrm{pCO}_{2}$ 42,8 mmHg; $\mathrm{PO}_{2} 264.80 \mathrm{mmol} / \mathrm{L} ; \mathrm{HCO}_{3}-19,40$ mmol.L; $\mathrm{TCO}_{2} 20,70 \mathrm{mmol} ; \mathrm{SaO}_{2} 99.5 \%$; Beecf -7.4 mmol/L (-2-2); Na $143 \mathrm{mmol} / \mathrm{L}$ (136145); Cl $92 \mathrm{mmol} / \mathrm{L}$ (96-108); K $3.19 \mathrm{mmol} / \mathrm{L}$ (3.50-5.10). MSCT scan: Subdural Hematome lobustemporoparietal kanan yang menyempitkan Sisterna ventrikel lateralis kanan dan deviasi midline sejauh 0,54 cm ke kiri. Foto Thorax AP: cor dan pulmo tak tampak kelainan, tak tampak fraktur dan dislokasi, Foto Pelvis AP : Tak tampak fraktur maupun dislokasi pada tulang-tulang pelvis, Foto cervical AP/Lateral: Paracervikal muscle spasm.

Selanjutnya oleh sejawat bedah saraf, pasien diputuskan untuk dilakukan kraniektomi evakuasi klot dan dekompresi di ruang operasi dengan persiapan pra operasi: informed consent, surat izin operasi, puasa, STATICS, obat anestesi dan emergensi, infus warmer, blood warmer, komponen darah, IV line bore besar, paska operasi ICU+ Ventilator. Pasien saat masuk ke ruang OK IGD sudah terintubasi dari Triage bedah, pipa endotrakeal langsung dihubungkan

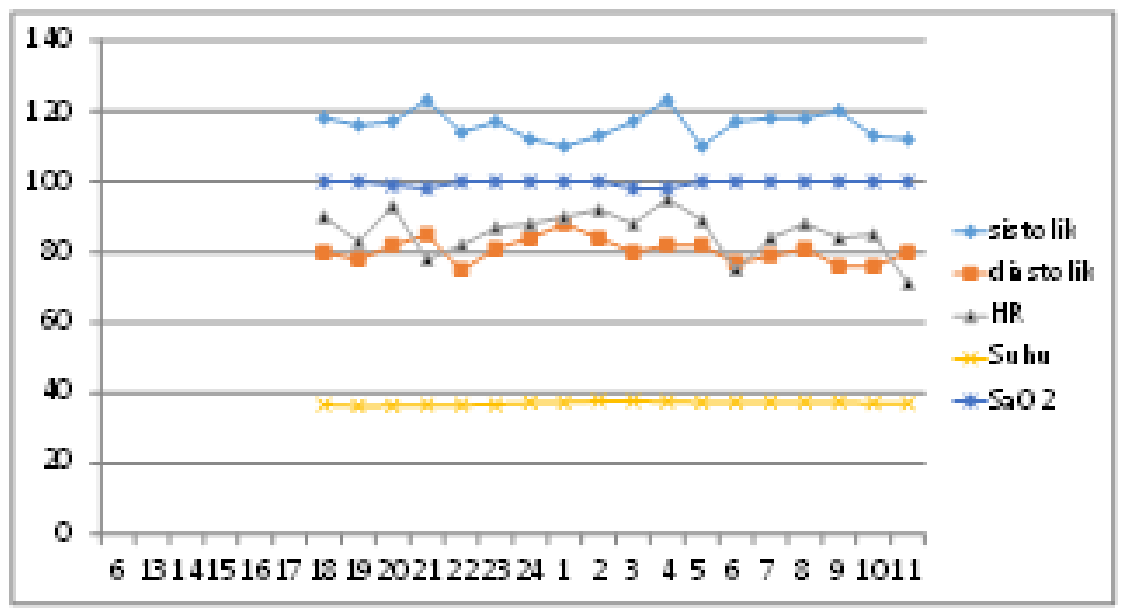

Gambar 2. Grafik Hemodinamik selama 18 jam Perawatan di ICU 

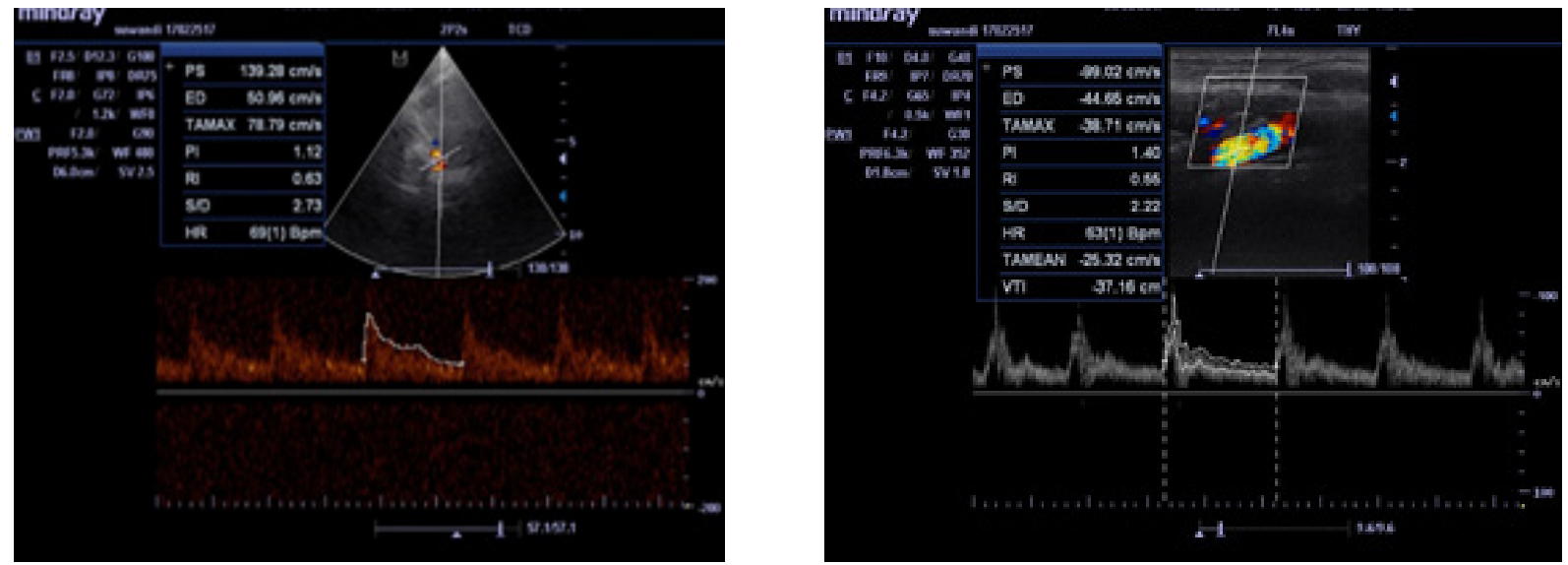

Gambar 3. Hasil Pemeriksaan TCD Pasien setelah 12 jam dirawat di ICU

ke mesin anastesi dengan volume kontrol, VT 560 ml, RR 12 x/menit, dengan FGF 2 L/menit, $\mathrm{FiO}_{2} 50 \%$. Pemeliharaan dengan sevoflurane 0,4 vol\%; Propofol TCI model schnider dengan target effect $2-3 \mu \mathrm{g} / \mathrm{ml}$; fentanyl total $250 \mu \mathrm{g}$; rocuronium intermittent $0,1 \mathrm{mg} / \mathrm{kgBB}$ tiap 30 menit. Paracetamol 1 gr iv, As Tranexamat 1 gr dan manitol $0,75 \mathrm{gr} / \mathrm{kgbb}$. Durante operasi. Fluktuasi tekanan darah 101-124/58-67 mmHg; HR 62-80 kali/menit, $\mathrm{SpO}_{2} 98-100 \%$, cairan kristaloid $1500 \mathrm{~mL}$, koloid $500 \mathrm{~mL}$, perdarahan $\pm 600 \mathrm{ml}$, urin $600 \mathrm{ml}$. Lama operasi 2 jam 15 menit. Hasil operasi: Dilakukan trepanasi pada daerah regio Fronto temporo parietal dextra perdarahan dan dilakukan evakuasi klot, kemudian dilakukan kraniectomi dan di evaluasi otak edema. Dilakukan buka dura, evaluasi SDH

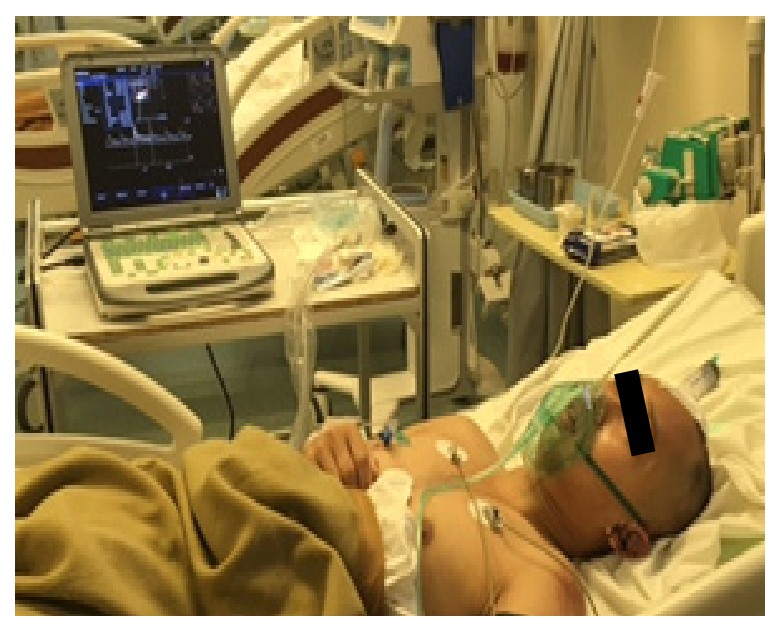

Gambar 4. Pasien Paska Extubasi di ICU dan rawat aktif perdarahan dengan surgical dan spongestan.

Pasca operatif pasien dirawat di ICU diposisikan head up $30^{\circ}$, dihubungkan dengan ventilator mode PC BIPAP dengan Pinsp 11, PEEP 5, RR 12 x/ mnt, $\mathrm{FiO}_{2} 40 \%$ didapatkan volume tidal 540-580 $\mathrm{ml}$, dengan saturasi $\mathrm{O}_{2}$ 99-100\%. Pemeliharaan cairan diberikan balance solution $2100 \mathrm{ml}$ dalam 24 jam. Pasien disedasi dengan TCI propofol target effect $1 \mu \mathrm{g} / \mathrm{ml}$, analgetik diberikan fentanyl $10 \mu \mathrm{g} / \mathrm{jam}$ dengan omeprazol $40 \mathrm{mg}$, cetriaxone 2 gram tiap 24 jam dan citicolin dan phenitoin $100 \mathrm{mg}$ tiap $8 \mathrm{jam}$. AGD 2 jam pasca pemasangan ventilator adalah: $\mathrm{PH} 7,41 ; \mathrm{pO}_{2} 189 \mathrm{mmHg}$; $\mathrm{pCO}_{2}$ 43,6 mmHg; $\mathrm{HCO}_{3}-26,90 \mathrm{mmol} / \mathrm{L} ; \mathrm{BE} 2,2$ $\mathrm{mmol} / \mathrm{L} ; \mathrm{SO}_{2} \mathrm{c} 98,4 \%$. Hemodinamik selama 18 jam pascaoperasi di ICU sesuai dengan grafik di gambar 2. Setelah dirawat selama 12 jam di ICU, pernapasan pasien mulai pulih kemudian mode ventilator dirubah menjadi CPAP dengan PEEP 5 dan $\mathrm{FiO}_{2}$ 40\% tekanan darah saat itu 124/87 mmHg dengan nadi $69 x / m e n i t$. Selanjutnya dilakukan pemeriksaan dengan TCD melalui temporal accoustic window kiri didapatkan hasil PS (peak sistolik) $139.28 \mathrm{~cm} / \mathrm{mnt}$, ED (end diastolik) 50,96 cm/menit dengan PI 1,12. Selain itu juga dilakukan pemeriksaan doppler pada carotis interna kiri didapatkan PS 99,02 cm/ menit, ED 44,65 cm/menit. Berdasarkan hasil tersebut maka sedasi TCI propofol dihentikan, 2 jam setelah sedasi dihentikan pasien membuka mata, selanjutnya dipasang T-pies selama 1 jam dan dilakukan extubasi dengan GCS 15. Dua 
jam paska extubasi dilakukan pemeriksaan AGD dengan hasil: $\mathrm{PH} 7,41 ; \mathrm{pO}_{2} 150,20 \mathrm{mmHg}$ ; $\mathrm{pCO}_{2} 38,6 \mathrm{mmHg} ; \mathrm{HCO}_{3}-23,40 \mathrm{mmol} / \mathrm{L}$; BE $0,7 \mathrm{mmol} / \mathrm{L} ; \mathrm{SO}_{2} \mathrm{c} 98,8 \%$. Pasien dipindahkan ke ruang rawat biasa setelah diobservasi selama 24 jam paska extubasi.

\section{Pembahasan}

Sampai saat ini penilaian GCS masih tetap digunakan untuk menilai keparahan dari cedera kepala. Dimana cedera kepala diklasifikasikan menjadi tiga group yaitu cedera kepala ringan dengan GCS 14-15, cedera kepala sedang dengan GCS 9-13, dan cedera kepala berat dengan GCS 3-8, dimana masing-masing group memerlukan tindakan dan keputusan medis yang berbeda. Seperti yang sudah disebutkan dipendahuluan hampir 50\% kecelakaan lalu lintas disertai dengan intoksikasi alkohol yang memiliki efek penekanan susunan saraf pusat yang selanjutnya mempengaruhi penilaian GCS tersebut ${ }^{5}$ sehingga ada kemungkinan terjadinya overtreatment ataupun undertreatment. Seseorang dikatakan mengalami intoksikasi alkohol akut yang extreme jika kadar alkohol didalam darahnya lebih dari $300 \mathrm{mg} / 100 \mathrm{ml}$, dan biasanya diikuti dengan gejala penurunan kesadaran sampai koma, reflex tendon yang menurun, hipotensi, hipotermia, dan penafasan yang melambat. ${ }^{6}$ Gejala yang ditimbulkan oleh intoksikasi alkohol sangat tergantung dari kadar alkohol didalam darah, oleh karena itu setiap negara memiliki kadar batas minimal alkohol didalam darah untuk mengemudikan kendaraan, sebagai contoh di kanada batasannya $50-80 \mathrm{mg} / 100 \mathrm{ml}$. Di Indonesia menurut Undang-Undang RI Nomor 22 Tahun 2009 tentang Lalu Lintas dan Angkutan Jalan. Pasal 106 UU ayat (1) menyebutkan: Setiap orang yang mengemudikan Kendaraan Bermotor di Jalan wajib mengemudikan kendaraannya dengan wajar dan penuh konsentrasi. Selanjutnya penjelasan pasal dan ayat ini menyebutkan: Yang dimaksud dengan "penuh konsentrasi" adalah setiap orang yang mengemudikan Kendaraan Bermotor dengan penuh perhatian dan tidak terganggu perhatiannya karena sakit, lelah, mengantuk, menggunakan telepon atau menonton televisi atau video yang terpasang di Kendaraan, atau meminum minuman yang mengandung alkohol atau obat-obatan sehingga memengaruhi kemampuan dalam mengemudikan Kendaraan. Oleh karena itu batas bawah atau minimal dari kadar alkohol di Indonesia untuk mengemudi adalah $0 \mathrm{mg} / 100 \mathrm{ml}$. Pasien ini secara undangundang sudah jelas melanggar aturan lalu lintas, karena walaupun masih bisa mengendarai sepeda motor, tetapi konsentrasinya pasti sudah terganggu karena adanya pengaruh alkohol.

Alkohol pada tingkat neurotransmiter bekerja pada banyak tempat di susunan saraf pusat yang melibatkan sistem excitatory dan inhibitory. Neurotransminer dan proses yang dipengaruhi diantaranya adalah Dopamine, Noradrenaline, Endogenous opioids, GABA, glutamate, L-type calcium channels, seretonin dan yang lainnya. ${ }^{6,7}$ Alkohol dapat mempotensiasikan aktivitas dari GABA melalui reseptor subunit GABA tertentu yang selanjutnya menyebabkan munculnya efek ansiolitik, amnesia, sedasi, kehilangan kesadaran yang tentunya mengganggu konsentrasi sesorang dalam mengemudikan kendaraan. Selanjutnya alkohol juga memblok reseptor exitatory NMDA, sehingga bekerja secara berlawanan dengan glutamate. Hal ini memberikan efek amnesia, penurunan perhatian dan kesadaran yang juga dapat mengganggu proses mengemudi. ${ }^{6,7}$ Selain itu alkohol juga menghambat pembukaan dari L-type calcium channels pada cerebellum yang selanjutnya menyebabkan efek motor incoordination seperti unsteady gait, penurunan konsentrasi dan gangguan regulasi tidur-bangun.? Efek penurunan GCS akibat alkohol disebabkan juga oleh kerja alkohol pada neurotransmiterneurotrasmiter diatas. Namun demikian pada penelitian deskriptif yang dilakukan pada 108,929 kasus kecelakaan yang melibatkan alkohol dengan kadar alkohol rata-rata $165 \mathrm{mg} /$ dl dari tahun 1994-2003. Didapatkan bahwa intoksikasi alkohol tidak menurunkan GCS secara signifikan pada pasien cedera kepala dengan usia muda. Disebutkan pada penelitian tersebut bahwa setelah distratifikasikan berdasarkan keparahan dari cedera kepalanya maka penurunan GCS yang diakibatkan oleh intoksikasi alkohol hanya sedikit lebih dari 1 point. Oleh karena itu disarankan untuk tidak memperhitungkan 
kadar alkohol didalam darah dalam mengambil keputusan untuk melakukan tindakan diagnostik maupun terapiutik seperti misalnya CT-scan ataupun ICP-monitoring. ${ }^{5}$

Pada Kasus ini keputusan medis yang diambil tidaklah mempertimbangkan kadar alkohol pasien didalam darah, penanganan medis yang dilakukan pada pasien ini seusai dengan guideline untuk cedera kepala berat, karena GCS pasien saat masuk adalah 7 sehingga diklasifikasikan sebagai cedera kepala berat. Namun demikian karena karena keterbatasan sarana maka tidak dilakukan pemasangan ICP monitoring. Pada pasien ini, juga diputuskan untuk dilakukan decompressive craniectomy (DC). DC termasuk dalam second tier therapies untuk penanganan peningkatan TIK pada guideline untuk cedera kepala berat (CKB). Pada pasien ini diputuskan untuk dilakukan DC karena pada pasien ini tidak dipasang monitoring ICP dan intraoperatif juga didapatkan otak pasien tegang dan edema. Selain itu menurut Brain Trauma Foundation, juga menyebutkan bahwa DC juga dapat menurunkan ICP dan meminimalkan perawatan di ICU.

Dua belas jam setelah dirawat di ICU pernapasan pasien mulai membaik sehingga mode ventilator dirubah menjadi CPAP, namun demikian saat itu pasien masih dibawah sedasi TCI propofol dengan target effect $1 \mu \mathrm{g} / \mathrm{ml}$. Sebelum memutuskan untuk menghentikan sedasinya maka dilakukan pemeriksaan TCD. TCD pertama kali digunakan pada tahun 1982 oleh Aaslid dkk sebagai teknik non invasif untuk memonitoring velocity aliran darah di basal cerebral arteri. ${ }^{8}$ TCD pada awalnya sering digunakan untuk mendiagnosa dan memonitoring vasospasme pada pasien dengan SAH. Dengan berjalannya waktu mulai ada banyak parameter-parameter tambahan yang didapatkan dari pemeriksaan TCD. Pada cedera kepala parameter-parameter yang dapat dinilai dengan TCD diantaranya aliran darah ke otak dengan menilai $\mathrm{mFV}$ nya; kemungkinan adanya hiperemia atau vasospasme dengan membandingkan mFV Middle Cerebral Arterie (MCA) dan internal carotid arterie (ICA); tekanan intrakranial yang dapat dinilai dari rumus yang melibatkan nilai PI, terutama pada rumah sakit-rumah sakit yang tidak memasang monitoring tekanan intrakranial dengan alasan apapun; noninvasif cerebral perfusion pressure (nCPP) menggunakan rumus yang melibatkan tekanan darah rata-rata, ED, dan mFV . Selain itu dengan TCD juga dapat dilakukan pemeriksaan untuk menilai keutuhan autoregulasi dari pembuluh darah otak.

Pada pasien ini, dari pemeriksaan TCD yang dilakukan pada temporal accoustic window kiri pada MCA didapatkan PS 139,28 cm/menit, ED 50,96 cm/mnt dengan PI 1,12. Dari data diatas maka $\mathrm{mFV}$ dapat dihitung dengan rumus $\mathrm{mFV}=(\mathrm{PS}+(2 \mathrm{xED})) / 3$ maka didapatkan $\mathrm{mFV}$ adalah $80,4 \mathrm{~cm} /$ menit. Nilai normal untuk $\mathrm{mFV}$ pada MCA adalah $55 \pm 12 \mathrm{~cm} /$ menit. $^{9} \mathrm{mFV}$ pada pasien ini sedikit lebih besar dari pada normal, namun tidak mengarah ke vasospasme karena nilainya masih kurang dari $120 \mathrm{~cm} /$ menit. Selain itu jika nilai $\mathrm{mFV}$ ini dibandingkan dengan nilai $\mathrm{mFV}$ yang didapatkan dari pemeriksaan doppler pada extracranial ICA yaitu $62,77 \mathrm{~cm} / \mathrm{mnt}$, maka Lindegaard ratio nya $(\mathrm{mFV} \mathrm{MCA} / \mathrm{mFV}$ extracranial ICA) adalah 1,2; yang mana untuk vasospasme LR nya bisanya $>3$. Jadi peningkatan darimFVpadapasieninikemungkinan diakibatkan karena pasien berada pada fase ke 2 dari cedera kepala yaitu fase hiperemia (1-2 hari setelah kejadian). Dari PI juga dapat dilihat perkiraan tekanan intrakranial pasien, dengan rumus 9,10 (11,1 x PI) -1,43 maka didapatkan estimasi TIK pasien ini adalah $11,00 \pm 4,2 \mathrm{mmHg}$. Selanjutnya pada saat dilakukan pemeriksaan didapatkan tekanan darah rata-rata $99 \mathrm{mmHg}$, oleh karena itu untuk mendapatkan estimasi CPP nya maka dimasukan ke dalam rumus eCPP $=($ meanABP $\mathrm{X}$ $(\mathrm{ED} / \mathrm{mFV}))+14 \mathrm{mmHg}^{9}$; di dapatkan hasil 76,30 $\mathrm{mmHg}$. Berdasarkan parameter-parameter diatas, pasien diputuskan untuk coba dibangunkan dan selanjutnya diextubasi dengan GCS 15.

Suatu hal yang menarik dari kasus ini adalah perbaikan yang cukup cepat pada pasien ini. Pasien masuk rumah sakit dengan GCS 7 dan didiagnosa dengan cedera kepala berat dan pasien diextubasi dengan GCS 15 kurang lebih hanya 18 jam setelah masuk ICU. Ada beberapa kemungkinan yang melatarbelakangi hal ini; 
kemungkinan besar pasien ini memang benar bukan seorang alkoholik, sehingga kemungkinan pada saat pertama kali masuk rumah sakit, pengaruh intoksikasi alkohol akut pada kesadaran pasien sangatlah besar, sehingga penilaian GCS yang dilakukan kurang akurat. Karena alkohol bekerja pada reseptor GABA yang menyebabkan penurunan kesadaran. Hal ini didukung oleh pemeriksaan CT-scannya dimana, walaupun didapatkan peningkatan tekanaan intrakranial, tetapi SDHnya ukurannya tidaklah terlalu besar. Selanjutnya seperti yang telah disebutkan diatas, salah satu kerja dari ethanol adalah dengan memblok reseptor NMDA, sehingga dapat mengurangi terjadinya exocitasi glutamat, dan menguntungkan bagi pasien ini.

\section{Simpulan}

Penanganan pasien dengan cedera kepala berat yang disertai dengan intoksikasi alkohol, sebaiknya tetap disesuikan dengan GCS masuknya, namun demikian pemantuaun lebih ketat sebaiknya dilakukan di ruang intensif, karena jika ternyata GCS tersebut dipengaruhi secara bermakna oleh alkohol, maka kemungkinan pasien akan mengalami perbaikan yang jauh lebih cepat dari biasanya. TCD dapat digunakan sebagai alat noninvasif untuk mengevaluasi aliran darah ke otak, tekanan intrakranial dan tekanan perfusi serebri.

\section{Daftar Pustaka}

1. Cunningham RM, Maio RF, Hill EM, Zink BJ. The effects of alcohol on head injury in the motor vehicle crash victim. Alcohol and alcoholism. 2002;37(3):236-40.

2. Scheenen ME, de Koning ME, van der Horn HJ, Roks G, Yilmaz T, van der Naalt J, dkk. Acute alcohol intoxication in patients with mild traumatic brain injury: characteristics, recovery, and outcome. Journal of neurotrauma. 2016;33(4):339-45.

3. Matta B, Czosnyka M. Transcranial doppler ultrasonography in anesthesia and neurosurgery. Dalam: Cottrell JE, Patel P, penyunting. Neuroanesthesia. edisi 6 . United States of America: Elsevier. 2017; 131-42.

4. Bouzat P, Oddo M, Payen J-F. Transcranial doppler after traumatic brain injury: is there a role? Current opinion in critical care. 2014;20(2):153-60.

5. Stuke L, Diaz-Arrastia R, Gentilello LM, Shafi S. Effect of alcohol on Glasgow Coma Scale in head-injured patients. Annals of surgery. 2007;245(4):651.

6. McIntosh C, Chick J. Alcohol and the nervous system. Journal of Neurology, Neurosurgery \& Psychiatry. 2004;75(suppl 3):iii16-iii21.

7. Costardi JVV, Nampo RAT, Silva GL, Ribeiro MAF, Stella HJ, Stella MB, dkk. A review on alcohol: from the central action mechanism to chemical dependency. Revista da Associação Médica Brasileira. 2015;61(4):381-7.

8. Moppett I, Mahajan R. Transcranial Doppler ultrasonography in anaesthesia and intensive care. Br. J. Anaesth. 2004;93(5):710-24.

9. Naqvi J, Yap KH, Ahmad G, Ghosh J. Transcranial doppler ultrasound: a review of the physical principles and major applications in critical care. International journal of vascular medicine. 2013;2013.

10. Bellner J, Romner B, Reinstrup P, Kristiansson K-A, Ryding E, Brandt L. Transcranial doppler sonography pulsatility index (PI) reflects intracranial pressure (ICP). Surgical neurology. 2004;62(1):45-51. 